\title{
Expert consensus on the rational clinical use of proprotein convertase subtilisin/kexin type 9 (PCSK9) inhibitors
}

\author{
Apostolos Achimastos, ${ }^{1}$ Theodoros Alexandrides, ${ }^{2}$ Dimitrios Alexopoulos, ${ }^{3}$ \\ Vasilios Athyros, ${ }^{4}$ Alexandra Bargiota, ${ }^{5}$ Eleni Bilianou, ${ }^{6}$ Christina Chrysochoou, ${ }^{7}$ \\ Evridiki Drogari, ${ }^{8}$ Moses Elisaf ${ }^{*},{ }^{9}$ Emanouel Ganotakis, ${ }^{10}$ Ioannis Goudevenos, ${ }^{11}$ \\ loannis loannidis, ${ }^{12}$ Genovefa Kolovou, ${ }^{13}$ Vasilios Kotsis, ${ }^{14}$ Ioannis Lekakis, ${ }^{15}$ \\ Evangelos Liberopoulos, ${ }^{16}$ Andreas Melidonis, ${ }^{17}$ Vasilios Nikolaou, ${ }^{18}$ George Ntaios, ${ }^{19}$ \\ Nikolaos Papanas, ${ }^{20}$ Stavros Pappas, ${ }^{21}$ Christos Pitsavos, ${ }^{22}$ Loukianos Rallidis, ${ }^{23}$ \\ Dimitrios Richter, ${ }^{24}$ Ioannis Skoumas, ${ }^{25}$ Nicolaos Tentolouris, ${ }^{26}$ Dimitrios Tousoulis, ${ }^{27}$ \\ Alexandros Tselepis, ${ }^{28}$ Konstantinos Tsioufis, ${ }^{29}$ Dimitrios Tziakas, ${ }^{30}$ \\ Konstantinos Tziomalos, ${ }^{31}$ Panagiotis Vardas, ${ }^{32}$ Charalabos Vlachopoulos, ${ }^{33}$ \\ Dimitrios Vlahakos ${ }^{34}$
}

\footnotetext{
${ }^{1}$ Professor of Internal Medicine, Medical School, National and Kapodistrian University of Athens, ${ }^{2}$ Professor of Internal Medicine-Endocrinology, Medical School, University of Patras, ${ }^{3}$ Professor of Cardiology, Medical School, University of Patras, ${ }^{4}$ Associate Professor of Internal Medicine, Past President of the Hellenic Atherosclerosis Society Aristotle University of Thessaloniki, ${ }^{5}$ Assistant Professor of Internal Medicine-Endocrinology, Medical School, University of Thessaly, ${ }^{6}$ Consultant-Cardiology, Head of Lipid Outpatient Clinic, "Tzaneio" General Hospital of Piraeus, 'Consultant Cardiology, 1st University Cardiology Clinic, "Hippokratio" General Hospital of Athens, ${ }^{8}$ Assistant Professor of Metabolic Pediatrics, Medical School, National and Kapodistrian University of Athens, ${ }^{9}$ Professor of Internal Medicine, Medical School, Past President of the Hellenic Atherosclerosis Society, University of loannina, ${ }^{10}$ Professor of Internal Medicine, Medical School, Past President of the Hellenic Atherosclerosis Society, University of Crete, ${ }^{11}$ Professor of Cardiology, Medical School, University of loannina, ${ }^{12}$ Consultant-Internal Medicine, Head of the Diabetes and Obesity Outpatient Clinics, General Hospital of Nea Ionia "Konstantopouleio-Patission", ${ }^{13}$ Consultant-Cardiology, Head of LDL Apheresis Unit and Lipid Outpatient Clinics, Past President of the Hellenic Atherosclerosis Society, President of the Hellenic College of Treatment of Atherosclerosis, Onassis Cardiac Surgery Center, ${ }^{14}$ Assistant Professor of Internal Medicine, Aristotle University of Thessaloniki, ${ }^{15}$ Professor of Cardiology, Medical School, National and Kapodistrian University of Athens, ${ }^{16}$ Assistant Professor of Internal Medicine, Medical School, University of loannina, ${ }^{17}$ Consultant-Internal Medicine, CoordinatorDirector of 1st Internal Medicine Clinic, "Tzaneio" General Hospital of Piraeus, ${ }^{18}$ Consultant-Cardiology, "Korgialenio Benakio" "HRC" Hospital, Athens, ${ }^{19}$ Assistant Professor of Internal Medicine, Medical School, University of Thessaly, ${ }^{20}$ Associate Professor of Internal Medicine, Medical School, Democritus University of Thrace, ${ }^{21}$ Internist-Diabetologist, President of the Institute for the Study, Research and Training on Diabetes Mellitus and Metabolic Diseases, Athens, ${ }^{22}$ Emeritus Professor of Cardiology, Medical School, National and Kapodistrian University of Athens, ${ }^{23}$ Associate Professor of Cardiology, Medical School, University of Athens, ${ }^{24}$ Director of Cardiology Department, Athens Euroclinic, President of the Hellenic Society of Lipidology and Atherosclerosis, Athens, ${ }^{25}$ Cosultant-Cardiology, Head of the Lipid Unit of the 1st

Address for correspondence:

Moses Elisaf, Professor of Internal Medicine, Medical School, University of Ioannina, 45110 Ioannina, Greece; Tel.: +30 2651-007 509, Fax: +30 2651-007 016, E-mail: melisaf54@gmail.com

Received: 04-12-2015, Accepted: 09-12-2015
} 
University Clinic, "Hippokratio" General Hospital of Athens, ${ }^{26}$ Associate Professor of Internal Medicine, Medical School, National and Kapodistrian University of Athens, ${ }^{27}$ Professor of Cardiology, Medical School, National and Kapodistrian University of Athens, ${ }^{28}$ Professor of Biochemistry-Clinical Chemistry, President of the Hellenic Atherosclerosis Society, University of loannina, ${ }^{29}$ Associate Professor of Cardiology, National and Kapodistrian University of Athens, ${ }^{30}$ Professor of Cardiology, Medical School, Democritus University of Thrace, ${ }^{31}$ Assistant Professor of Medicine, Medical School, Aristotle University of Thessaloniki, ${ }^{32}$ Professor of Cardiology, Medical School, Past President of the European Cardiology Society, University of Crete, ${ }^{33}$ Associate Professor of Cardiology, President of the European Society of Cardiology working Group for Peripheral Circulation, National and Kapodistrian University of Athens, ${ }^{34}$ Associate Professor of Nephrology, National and Kapodistrian University of Athens; Greece

\begin{abstract}
Two proprotein convertase subtilisin/kexin type 9 (PCSK9) inhibitors, evolocumab and alirocumab, have recently been approved by both the Food and Drug Administration (FDA) and the European Medicines Agency (EMA) for the treatment of hypercholesterolemia. These fully human monoclonal antibodies selectively block PCSK9, thus permitting the low-density lipoprotein (LDL) receptor to effectively recycle to the surface of liver cells. The administration of these antibodies leads to robust LDL cholesterol (LDL-C) lowering by 50-60\% on top of maximum hypolipidemic treatment. At least 4 randomized, placebo-controlled studies are under way and will address the question of whether the administration of these PCSK9 inhibitors is associated with a significant reduction of cardiovascular events. Because of the high cost associated with the use of these medications it is very important to consider which patients may gain the most benefit, at least until the results of outcome studies are available. In this Consensus paper, 34 clinicians/scientists define 3 groups of patients that should be currently considered as candidates for the use of these novel drugs. These include: 1a. Adults with established cardiovascular disease and LDL-C $\geq 100 \mathrm{mg} / \mathrm{dL}$ while on lifestyle modifications and maximally tolerated hypolipidemic treatment, i.e. high-intensity statin + ezetimibe, $1 \mathrm{~b}$. Adults with diabetes and established cardiovascular disease or chronic kidney disease or target organ damage and LDL-C $\geq 100 \mathrm{mg} / \mathrm{dL}$ while on lifestyle modifications and maximally tolerated hypolipidemic treatment, i.e. high-intensity statin + ezetimibe, 2. Adults with familial hypercholesterolemia (FH) without established cardiovascular disease and LDL-C $\geq 130 \mathrm{mg} / \mathrm{dL}$ while on lifestyle modifications and maximally tolerated hypolipidemic treatment, i.e. high-intensity statin + ezetimibe (evolocumab is also indicated in children above 12 years with homozygous FH), and 3. Adults at high or very high cardiovascular risk who are statin intolerant and have an LDL-C $\geq 100$ and $\geq 130 \mathrm{mg} / \mathrm{dL}$, respectively, while on any tolerated hypolipidemic treatment.
\end{abstract}

Key words: Cardiovascular disease, Diabetes, Ezetimibe, Familial hypercholesterolemia, High-risk, LDL cholesterol, PCSK9, Statin intolerance, Statins

\section{INTRODUCTION}

Proprotein convertase subtilisin/kexin type 9 (PCSK9) plays an important role in lipoprotein metabolism because it binds and accelerates the cellular degradation of low-density lipoprotein (LDL) receptors, thus preventing their recycling to the hepatocyte surface. This effect results in the increase of plasma LDL cholesterol (LDL-C) levels. ${ }^{1-7}$
The administration of fully human monoclonal antibodies that bind plasma PCSK9 of patients treated with statins (with or without ezetimibe) results in an additional reduction of LDL-C by $50-60 \%$ and the achievement of lipid-lowering therapy goals in the vast majority of high-risk patients. ${ }^{7-19}$ Clinical and experimental data have shown that statins, as opposed to their ability to reduce LDL-C levels, increase 
PCSK9 levels. ${ }^{1}$ This increase is due to the activation of the Sterol Regulatory Element-Binding-Protein-2 (SREBP-2), a transcription factor that induces gene expression and therefore increases the levels of LDL receptors as well as of PCSK9. ${ }^{1}$ These findings reinforce the clinical trial data showing that inhibition of PCSK9 with monoclonal antibodies enhances the lipid-lowering effect of statins. Moreover, it has been shown that PCSK9 inhibitors decrease levels of lipoprotein (a) [Lp(a)] by approximately $25 \%$, triglycerides by $9 \%$, non-high density lipoprotein (HDL) cholesterol by $52 \%$ and apolipoprotein B by $43 \%$ as well as increase HDL cholesterol (HDL-C) levels by $9 \%$ and apolipoprotein AI by $5 \%{ }^{8-20}$

Three large meta-analyses of PCSK9 inhibitors, evolocumab and alirocumab (meta-analysis of 24 randomized studies by Navarese et al, 25 randomized studies by Zhang et al and 17 randomized studies by Lipinski et al), confirmed the efficacy and safety of both drugs, without differences regarding serious adverse events among patients treated with evolocumab or alirocumab and placebo. ${ }^{8-10}$ Of note, injection-site reactions and neurocognitive adverse events were more frequent in patients on PCSK9 inhibitors compared with placebo. ${ }^{10}$ The possible association of PCSK9 inhibitors with neurocognitive adverse events is under scrutiny in ongoing studies.

It is of particular interest that two studies recently published (ODYSSEY LONG TERM \& OSLER studies) showed that administration of both drugs, apart from the well tolerated reduction in LDL-C, resulted in a significant $(50 \%)$ reduction in cardiovascular $(\mathrm{CV})$ events (treatment duration 1 year, starting LDL-C levels of $\sim 120 \mathrm{mg} / \mathrm{dL}) .{ }^{19,20}$ However, these studies were not designed to evaluate the effect of the drugs on $\mathrm{CV}$ events, while the number of $\mathrm{CV}$ events recorded during treatment was low and the time of prospective follow-up of patients was limited. Ongoing studies will answer the question whether the reduction of LDL-C through PCSK9 inhibition leads to a proportional reduction of $\mathrm{CV}$ events in cases of long-term administration, without adverse events.

Regulatory authorities in the USA and Europe [Food and Drug Administration (FDA) and European Medicines Agency (EMA)] have approved the administration of these drugs to adult patients with primary hypercholesterolemia (heterozygous familial and non-familial) or mixed dyslipidemia, as adjunct treatment to diet:

- In combination with a statin or statin with other lipid lowering therapies in patients unable to reach LDL-C goals with the maximum tolerated dose of a statin, or,

- Alone or in combination with other lipid-lowering therapies in patients who are statin-intolerant or for whom a statin is contraindicated.

Evolocumab has received an additional indication in adolescents over 12 years old with homozygous familial hypercholesterolemia $(\mathrm{FH})$ in combination with other lipid-lowering treatments.

The drugs are administered as subcutaneous injections every 2 weeks (evolocumab $140 \mathrm{mg}$ and alirocumab 75 or $150 \mathrm{mg}$ ) or 4 weeks (evolocumab $420 \mathrm{mg})$.

\section{Patients who could benefit from treatment with PCSK9 inhibitors}

Until the announcement-publication of the prospective randomized clinical trials that will confirm the effect of these drugs on CV morbidity and mortality, it is proposed that their prescription be limited to specific patient groups at very high risk who are expected to benefit from the treatment.

The following guidelines are consistent with the recent recommendations of the US National Lipid Association (NLA) and are summarized in Table 1. ${ }^{11}$ It is to be noted that patient adherence with already administered lipid-lowering therapy should always be examined first. The patient groups that are expected to benefit from treatment are: (1) patients with $\mathrm{FH}$, (2) patients with established vascular disease and very high-risk diabetic patients who do not achieve the hypolipidemic treatment goals with the maximum available lipid-lowering therapy (high doses of effective statins + ezetimibe), and (3) patients intolerant to statins. Patients with $\mathrm{FH}$ are at high $\mathrm{CV}$ risk because of very high levels of LDL-C. These patients often do not achieve the goals of hypolipidemic treatment in daily clinical practice. It must be underlined that a percentage of patients display intolerance to statins, i.e. myalgia with or without an increase in muscle 
Table 1. Profiles of eligible patients for administration of monoclonal antibodies against PCSK9 until the completion of large randomized clinical trials with cardiovascular outcomes

\begin{tabular}{|c|c|c|}
\hline Group of high- to very high-risk individuals & & Ultimate treatment goal \\
\hline $\begin{array}{l}\text { 1a. Adult patients with established atherosclerotic } \mathrm{CV} \\
\text { disease (coronary, carotid or peripheral vessels) } \\
\text { and LDL-C } \geq 100 \mathrm{mg} / \mathrm{dL} \\
\text { 1b. Diabetic patients with known CV disease or chronic } \\
\text { kidney disease (estimated glomerular filtration rate } \\
\leq 60 \mathrm{~mL} / \mathrm{min} / 1.73 \mathrm{~m}{ }^{2} \text { and } / \text { or albuminuria for } \\
\text { at least } 3 \mathrm{months} \text { ) or other target organ damage } \\
\text { and LDL-C } \geq 100 \mathrm{mg} / \mathrm{dL}\end{array}$ & $\begin{array}{l}\text { Under appropriate health-diet and } \\
\text { pharmaceutical treatment with the } \\
\text { maximum tolerated dose of effective } \\
\text { statin (atorvastatin } 40 / 80 \mathrm{mg} \text { or } \\
\text { rosuvastatin } 20 / 40 \mathrm{mg} \text { ) + ezetimibe } \\
10 \mathrm{mg}\end{array}$ & LDL-C $<70 \mathrm{mg} / \mathrm{dL}$ \\
\hline $\begin{array}{l}\text { 2. Adult patients FH without known atherosclerotic } \\
\text { cardiovascular disease and LDL-C } \geq 130 \mathrm{mg} / \mathrm{dL} *\end{array}$ & $\begin{array}{l}\text { Under treatment with the maximum } \\
\text { tolerated dose of effective statin } \\
\text { (atorvastatin } 40 / 80 \mathrm{mg} \text { or rosuvastatin } \\
20 / 40 \mathrm{mg} \text { ) + ezetimibe } 10 \mathrm{mg}\end{array}$ & LDL-C $<100 \mathrm{mg} / \mathrm{dL}$ \\
\hline \multirow{2}{*}{$\begin{array}{l}\text { 3. High- or very high-risk patients (HELLENIC } \\
\text { SCORE }>5 \% \text { or }>10 \% \text {, respectively) who are } \\
\text { intolerant to statins and have LDL-C } \geq 130 \\
\text { or } \geq 100 \mathrm{mg} / \mathrm{dL} \text {, respectively }\end{array}$} & \multirow[t]{2}{*}{$\begin{array}{l}\text { Under any tolerated lipid-lowering } \\
\text { treatment }\end{array}$} & $\begin{array}{l}\text { LDL- } C<70 \mathrm{mg} / \mathrm{dL} \\
\text { in very high-risk patients }\end{array}$ \\
\hline & & $\begin{array}{l}\mathrm{LDL}-\mathrm{C}<100 \mathrm{mg} / \mathrm{dL} \\
\text { in high-risk patients }\end{array}$ \\
\hline
\end{tabular}

* Evolocumab has received additional indication in adolescents over 12 years old with homozygous FH in combination with other lipid-lowering treatments.

Table 2. Dutch Lipid Clinic Network diagnostic criteria for Familial Hypercholesterolemia

\begin{tabular}{|c|c|c|}
\hline \multicolumn{2}{|l|}{ Criteria } & Score \\
\hline Family history & $\begin{array}{l}\text { First degree relative with: } \\
\text { - Known premature coronary or vascular disease (men aged }<55 \text { years, women aged }<60 \text { years) } \\
\text { - LDL-C above the } 95 \text { th percentile for age and gender } \\
\text { - Tendinous xanthomata and/or corneal arcus } \\
\text { First degree relative }<18 \text { years with LDL-C above the } 95 \text { th percentile for age and gender }\end{array}$ & $\begin{array}{l}1 \\
1 \\
2 \\
2\end{array}$ \\
\hline Clinical history & $\begin{array}{l}\text { Patients with premature coronary artery disease (men aged }<55 \text { years, women aged }<60 \text { years) } \\
\text { Patients with premature peripheral arterial disease or ischemic stroke (men aged }<55 \text { years, } \\
\text { women aged }<60 \text { years) }\end{array}$ & $\begin{array}{l}2 \\
1\end{array}$ \\
\hline Physical examination & $\begin{array}{l}\text { Tendinous xanthomata } \\
\text { Corneal arcus prior to age } 45 \text { years }\end{array}$ & $\begin{array}{l}6 \\
4\end{array}$ \\
\hline Laboratory check & $\begin{array}{l}\text { LDL-C, mg/dL (mmol/L) } \\
\cdot \geq 330(\geq 8.5) \\
\cdot 250-329(6.5-8.4) \\
\cdot 190-249(5.0-6.4) \\
\cdot 155-189(4.0-4.9)\end{array}$ & $\begin{array}{l}8 \\
5 \\
3 \\
1\end{array}$ \\
\hline DNA analysis & Functional mutation in the LDL receptor, apolipoprotein B or PCSK9 gene & 8 \\
\hline $\begin{array}{l}\text { Total score } \\
>8 \\
6-8 \\
3-5\end{array}$ & $\begin{array}{l}\text { Diagnosis } \\
\text { Definite FH } \\
\text { Probable FH } \\
\text { Possible FH }\end{array}$ & \\
\hline
\end{tabular}

enzymes, which makes it difficult to continue treatment with statins or to administer high doses of these drugs. ${ }^{21-25}$

\section{Diagnosis of $\mathrm{FH}$}

The diagnosis of heterozygous FH is set clinically using the Dutch criteria (Table 2 and FH score in 
App Store (https://appsto.re/gr/wF4Q7.i), FH score in Google Store (https://play.google.com/store/apps/ details ?id=com.ajjumax.helleniccalculat) and Download in desktop (http://web.alphabit.gr/FHCalculator/index.html) and when the patient has a score $\geq 6$ (probable or definite $\mathrm{FH}$ ). ${ }^{26-38}$

The Hellenic Atherosclerosis Society has already initiated a nationwide registry of patients with $\mathrm{FH}$ (HELLAS FH Registry - Hellenic Registry of Patients with $\mathrm{FH}$ ). The inclusion of any patient in this registry also confirms its diagnosis.

\section{Diagnosis of statin intolerance}

The diagnosis of statin intolerance is set in patients who: (a) display significant increases in creatine kinase $(\mathrm{CK})>5$ times of the upper limit reference values, and/or, (b) irrespective of any increase in CK, display muscle symptoms which may be attributed to statins (pain, fatigue, weakness, cramps) and after the exclusion of any other factors which could cause similar symptoms (Table 3 ) and/or any possible interactions of the co-administered drugs have been excluded (Table 4).

In order to confirm possible statin intolerance, a sequential administration of at least 2 different statins starting at low doses followed by a careful dosage up-titration over a few weeks is required (Table 5). The improvement of symptoms following statin treatment discontinuation and their reappearance with the re-administration of the same or a different statin reinforce the diagnosis of statin intolerance. The therapeutic options in patients intolerant to statins before administration of the PCSK9 inhibitors are shown in Table $6 .{ }^{21-25}$

Table 3. Causes to be excluded in patients with muscular pains and/or CK increase before these findings are attributed to statins.
1. Exercise-Muscle strain
2. Intramuscular injections
3. Drugs (cocaine, heroin, amphetamines) - Alcohol
4. Hypothyroidism
5. Infections
6. Electrolyte disorders (e.g. hypokalemia)
7. Metabolic myopathies
8. Inflammatory and autoimmune myositis

Table 4. Drug interactions of statins
1. Fibrates (mainly gemfibrozil - not fenofibrate)
2. Coumarin anticoagulants
3. Cyclosporine
4. Erythromycin and other macrolides (clarithromycin)
5. Itraconazole and other antifungal medicines
6. Antidepressants (nefazodone)
7. Protease inhibitors
8. Dihydropyridines, as well as diltiazem/verapamil (mainly with simvastatin)
9. Amiodarone (mainly with simvastatin/lovastatin)
10. Grapefruit juice
11. Drugs that induce the activity of CYP3A4 (phenytoin, ri- fampicin)

Table 5. Statins marketed in Greece (approved dose range)

\begin{tabular}{lc}
\hline Statin & Dose range \\
\hline Atorvastatin & $10-80 \mathrm{mg}$ \\
Lovastatin & $20-80 \mathrm{mg}$ \\
Pitavastatin & $1-4 \mathrm{mg}$ \\
Pravastatin & $10-40 \mathrm{mg}$ \\
Rosuvastatin & $5-40 \mathrm{mg}$ \\
Simvastatin & $10-40 \mathrm{mg}$ \\
Fluvastatin & $20-80 \mathrm{mg}$ \\
\hline
\end{tabular}

Table 6. Therapeutic options in patients intolerant to statins prior to the administration of PCSK9 inhibitors.

1. Aggressive health-diet changes.

2. Administration of ezetimibe (10 mg/day).

3. Administration of a combination of ezetimibe ( $10 \mathrm{mg} /$ day) with colesevelam (3.75 g/day). The expected reduction in LDL-C is $30 \%$. Alternatively, a combination of ezetimibe with fenofibrate may be administered.

4. Potential careful administration of pravastatin $20 \mathrm{mg} /$ day or fluvastatin $40 \mathrm{mg} /$ day.

5. Administration of rosuvastatin $5 \mathrm{mg}$ or atorvastatin $10 \mathrm{mg}$ every other day or twice per week or once per week, in combination with daily ezetimibe.

6. Measurement of vitamin $25(\mathrm{OH}) \mathrm{D}_{3}$ levels and supplementation in cases of reduced levels, although the evidence is limited.

7. Dealing with the factors listed in Table 3.

\section{FINANCIALAND COMPETING INTEREST DISCLOSURE}

This consensus was written independently and 
was not financed by the pharmaceutical industry. Some authors have given lectures and participated in congresses and advisory boards of various pharmaceutical companies; however, they have no conflict of interest in terms of employment, stock ownership or options, grants, or patents received or pending, or royalties. No writing assistance was utilized in the production of this consensus.

\section{ACKNOWLEDGEMENT}

This consensus was published in Greek in the Hellenic Journal of Atherosclerosis (Hellenic J Atheroscler 2015, 6(Suppl): 3-8). After agreement of the two Editors-in-Chief it is published in English in an extended form in Hormones.

\section{REFERENCES}

1. Careskey HE, Davis RA, Alborn WE, Troutt JS, Cao G, Konrad RJ, 2008 Atorvastatin increases human serum levels of proprotein convertase subtilisin/kexin type 9 . J Lipid Res 49: 394-398.

2. Elisaf M, Liberopoulos E, Pitsavos C, et al, 2014 Updated guidelines of the Hellenic Society of Atherosclerosis for the diagnosis and treatment of dyslipidemia-2014. Hellenic J Atheroscler 5: 151-163 [in Greek]

3. European Association for Cardiovascular Prevention \& Rehabilitaiton, Reiner Z, Catapano AL, De Backer G, et al, 2011 ESC/EAS Guidelines for the management of dyslipidaemias: the Task Force for the management of dyslipidaemias of the European Society of Cardiology (ESC) and the European Atherosclerosis Society (EAS). Eur Heart J 32: 1769-1818.

4. Stone NJ, Robinson JG, Lichtenstein AH, et al, 2014 2013 ACC/AHA guideline on the treatment of blood cholesterol to reduce atherosclerotic cardiovascular risk in adults: a report of the American College of Cardiology/American Heart Association Task Force on Practice Guidelines. Circulation 129: Supple 2: 1-45.

5. Anderson TJ, Gregoire J, Hegele RA, et al, 20132012 update of the Canadian Cardiovascular Society guidelines for the diagnosis and treatment of dyslipidemia for the prevention of cardiovascular disease in the adult. Can J Cardiol 29: 151-167.

6. Grundy SM, Arai H, Barter P, et al, 2014 An International Atherosclerosis Society Position Paper: global recommendations for the management of dyslipidemia-full report. J Clin Lipidol 8: 29-60.

7. American Diabetes Association, 2015 Standards of Medical Care in Diabetes - 2015. Diabetes Care 38: Suppl 1: 49-57.

8. Navarese EP, Kolodziejczak M, Schulze V, et al, 2015
Effects of Proprotein Convertase Subtilisin/ KexinType 9. Antibodies in adults with hypercholesterolemia: a systematic review and meta-analysis. Ann Intern Med 163: $40-51$

9. Zhang XL, et al, 2015 Safety and efficacy of anti-PCSK9 antibodies: a metaanalysis of 25 randomized, controlled trials. BMC Med 13: 123.

10. Lipinski MJ, Benedetto U, Escarcega RO, et al, 2016 The impact of proprotein convertase subtilisinkexin type 9 serine protease inhibitors on lipid levels and outcomes in patients with primary hypercholesterolaemia: a network meta-analysis. Eur Heart J 37: 536-545

11. Jacobson TA, Maki KC, Orringer CE, et al, 2015 National Lipid Association Recommendations for PatientCentered Management of Dyslipidemia: Part 2. J Clin Lipidol 9: Suppl 1: 1-122

12. Robinson JG, Nedergaard BS, Rogers WJ, et al, 2014 Effect of evolocumab or ezetimibe added to moderateor high-intensity statin therapy on LDL-C lowering in patients with hypercholesterolemia: the LAPLACE-2 randomized clinical trial. JAMA 311: 1870-1882.

13. Stein EA, Mellis S, Yancopoulos GD, et al, 2012 Effect of a monoclonal antibody to PCSK9 on LDL cholesterol. N Engl J Med 366: 1108-1118.

14. Blom DJ, Hala T, Bolognese M, et al, 2014 A 52-week placebo-controlled trial of evolocumab in hyperlipidemia. N Engl J Med 370: 1809-1819.

15. Stroes E, Colquhoun D, Sullivan D, et al, 2014 AntiPCSK9 antibody effectively lowers cholesterol in patients with statin intolerance: the GAUSS-2 randomized, placebo-controlled phase 3 clinical trial of evolocumab. J Am Coll Cardiol 63: 2541-2548.

16. Koren MJ, Lundqvist P, Bolognese M, et al, 2014 AntiPCSK 9 monotherapy for hypercholesterolemia: the MENDEL-2 randomized, controlled phase III clinical trial of evolocumab. J Am Coll Cardiol 63: 2531-2540.

17. Koren MJ, Giugliano RP, Raal FJ, et al, 2014 Efficacy and safety of longer term administration of evolocumab (AMG 145) in patients with hypercholesterolemia: 52week results from the Open-Label Study of Long-Term Evaluation Against LDL-C (OSLER) randomized trial. Circulation 129: 234-243.

18. Raal FJ, Honarpour N, Blom DJ, et al, 2015 Inhibition of PCSK9 with evolocumab in homozygous familial hypercholesterolaemia (TESLA Part B): a randomised, double-blind, placebo-controlled trial. Lancet 385: 341350 .

19. Sabatine MS, Giugliano RP, Wiviott SD et al, OpenLabel Study of Long-Term Evaluation against LDL Cholesterol (OSLER) Investigators 2015 Efficacy and safety of evolocumab in reducing lipids and cardiovascular events. N Engl J Med 372: 1500-1509

20. Robinson JG, Farnier M, Krempf M, et al, ODYSSEY LONG TERM Investigators, 2015 Efficacy and safety of alirocumab in reducing lipids and cardiovascular events. N Engl J Med 372: 1489-1499. 
21. Stroes ES, Thompson PD, Corsini A, et al, European Atherosclerosis Society Consensus Panel, 2015 Statinassociated muscle symptoms: impact on statin therapyEuropean Atherosclerosis Society Consensus Panel Statement on Assessment, Aetiology and Management. Eur Heart J 36: 1012-1022.

22. Guyton JR, Bays HE, Grundy SM, Jacobson TA, 2014 The National Lipid Association Statin Intolerance Panel. An assessment by the Statin Intolerance Panel: 2014 update. J Clin Lipidol 8: Suppl: 72-81.

23. Rosenson RS, Baker SK, Jacobson TA, et al, 2014 The National Lipid Association's Muscle Safety Expert Panel. An assessment by the Statin Muscle Safety Task Force: 2014 update. J Clin Lipidol 8: Suppl: 58-71.

24. Mancini GB, Tashakkor AY, Baker S, et al, 2013 Diagnosis, prevention, and management of statin adverse effects and intolerance: Canadian Working Group Consensus update. Can J Cardiol 29: 1553-1568.

25. Banach M, Rizzo M, Toth PP, et al, 2015 Statin intolerance - an attempt at a unified definition. Position paper from an International Lipid Expert Panel. Arch Med Sci 11: 1-23.

26. Raal FJ, Stein EA, Dufour R et al, RUTHERFORD-2 Investigators, 2015 PCSK9 inhibition with evolocumab (AMG 145) in heterozygous familial hypercholesterolaemia (RUTHERFORD-2): a randomised, double-blind, placebo-controlled trial. Lancet 385: 331-340

27. Nordestgaard BG, Chapman MJ, Humphries SE, et al, European Atherosclerosis Society Consensus Panel, 2013 Familial hypercholesterolaemia is underdiagnosed and undertreated in the general population: guidance for clinicians to prevent coronary heart disease: consensus statement of the European Atherosclerosis Society. Eur Heart J 34: 3478-3490.

28. Roth EM, Taskinen MR, Ginsberg HN, et al, 2014 Monotherapy with the PCSK9 inhibitor alirocumab versus ezetimibe in patients with hypercholesterolemia: results of a 24 week, double-blind, randomized Phase 3 trial. Int J Cardiol 176: 55-61.

29. Boekholdt SM, Hovingh GK, Mora S et al, 2014 Very low levels of atherogenic lipoproteins and the risk for cardiovascular events: a meta-analysis of statin trials. J Am Coll Cardiol 64: 485-494.

30. Everett BM, Smith RJ, Hiatt WR, 2015 Reducing LDL with PCSK9 Inhibitors - The Clinical Benefit of Lipid Drugs. N Engl J Med 373: 1588-1591.

31. Giugliano RP, Sabatine MS, 2015 Are PCSK9 inhibitors the next breakthrough in the cardiovascular field? J Am Coll Cardiol 65: 2638-2651.

32. Kastelein JJ, Ginsberg HN, Langslet G, et al, 2015 ODYSSEY FH I and FH II: 78 week results with alirocumab treatment in 735 patients with heterozygous familial hypercholesterolaemia. Eur Heart J 36: 2996-3003.

33. Bays H, Gaudet D, Weiss R, et al, 2015 Alirocumab as add-on to atorvastatin versus other lipid treatment strategies: ODYSSEY OPTIONS I Randomized Trial. J Clin Endocrinol Metab 100: 3140-3148.

34. Kereiakes DJ, Robinson JG, Cannon CP, et al, 2015 Efficacy and safety of the proprotein convertase subtilisin/kexin type 9 inhibitor alirocumab among high cardiovascular risk patients on maximally tolerated statin therapy: The ODYSSEY COMBO I study. Am Heart J 169: 906-915.e13.

35. Verbeek R, Stoekenbroek RM, Hovingh GK, 2015 PCSK9 inhibitors: Novel therapeutic agents for the treatment of hypercholesterolemia. Eur J Pharmacol 7 63(Pt A): 38-44.

36. Cannon CP, Cariou B, Blom D et al, ODYSSEY COMBO II Investigators, 2015 Efficacy and safety of alirocumab in high cardiovascular risk patients with inadequately controlled hypercholesterolaemia on maximally tolerated doses of statins: the ODYSSEY COMBO II randomized controlled trial. Eur Heart J 36: 1186-1194.

37. Schwartz GG, Bessac L, Berdan LG, et al, 2014 Effect of alirocumab, a monoclonal antibody to PCSK9, on long-term cardiovascular outcomes following acute coronary syndromes: rationale and design of the ODYSSEY outcomes trial. Am Heart J 168: 682-689.

38. Panagiotakos DB, Fitzgerald AP, Pitsavos C, et al, 2007 Statistical modeling of 10-year fatal cardiovascular disease risk in Greece: the Hellenic SCORE (a calibration of the ESC Score project). Hellenic J Cardiol 48: 55-63. 